\title{
Halophilic bacteria are colonizing the exhibition areas of the Capuchin Catacombs in Palermo, Italy
}

\author{
G. Piñar · L. Kraková · D. Pangallo • \\ D. Piombino-Mascali $\cdot$ F. Maixner • \\ A. Zink $\cdot$ K. Sterflinger
}

Received: 3 February 2014/ Accepted: 27 April 2014/Published online: 27 May 2014

(C) The Author(s) 2014. This article is published with open access at Springerlink.com

\begin{abstract}
The Capuchin Catacombs of Palermo, Italy, contain over 1800 mummies dating from the 16th to 20th centuries $\mathrm{AD}$. Their environment is not conducive to the conservation of the remains due to, among other factors, water infiltration, which is producing salt efflorescences on the walls. A multiphasic approach was applied to investigate the halophilic microbiota present in the Catacombs. Enrichment cultures were conducted on media containing different $\mathrm{NaCl}$ concentrations, ranging from 3 to $20 \%$. For screening of the strains, the following two PCR-based methods were used and compared: fluorescence internal transcribed spacer PCR (f-ITS) and random amplification of polymorphic DNA (RAPD) analyses. Results derived from RAPD profiles were shown to be slightly more discriminative than those derived from f-ITS. In addition, the proteolytic and cellulolytic abilities were screened through the use of plate assays, gelatin agar and Ostazin Brilliant Red H-3B (OBR-HEC), respectively. Many of the strains isolated from the wall samples displayed proteolytic activities,
\end{abstract}

Communicated by A. Oren.

G. Piñar $(\bowtie) \cdot K$. Sterflinger

VIBT-Vienna Institute of BioTechnology, Department of

Biotechnology, University of Natural Resources and Life

Sciences, Muthgasse 11, 1190 Vienna, Austria

e-mail: guadalupe.pinar@boku.ac.at

L. Kraková · D. Pangallo

Institute of Molecular Biology, Slovak Academy of Sciences,

Bratislava, Slovakia

D. Piombino-Mascali

Department of Cultural Heritage and of Sicilian Identity,

Sicilian Region, Palermo, Italy

F. Maixner $\cdot$ A. Zink

EURAC-Institute for Mummies and the Iceman, Bolzano, Italy such as all strains belonging to the genera Bacillus, Virgibacillus and Arthrobacter, as well as some strains related to the genera Oceanobacillus, Halobacillus and Idiomarina. In addition, many of the strains isolated from materials employed to stuff the mummies showed cellulolytic activities, such as those related to species of the genera Chromohalobacter and Nesterenkonia, as well as those identified as Staphylococcus equorum and Halomonas sp. Furthermore, many of the strains were pigmented ranging from yellow to a strong pink color, being directly related to the discoloration displayed by the materials.

Keywords Halophilic bacteria - Proteolytic capabilities . Cellulolytic capabilities · Discoloration - f-ITS · RAPD sequencing analyses

\section{Introduction}

Traditionally, halophilic microorganisms have been isolated from salted foods and hypersaline environments, mainly saline lakes, salterns and saline soils (Ventosa 2006). This group of microorganisms can be classified on the basis of their optimal $\mathrm{NaCl}$ requirements in different categories: slightly (optimal $\mathrm{NaCl}$ requirement of 1-3\%), moderately (optimal $\mathrm{NaCl}$ requirement of 3-15\%) and extremely halophilic which require more than $15 \%$ of $\mathrm{NaCl}$ for optimal growth (Kushner 1978). Classically, two different groups of halophilic microorganisms have been identified in hypersaline environments: extremely halophilic archaea (haloarchaea) and moderately halophilic bacteria. Halophilic bacteria are currently represented by a large number of species included on different phylogenetic branches, reflecting their broad metabolic activities (Ventosa et al. 2012). In this study, no hypersaline lake or other 


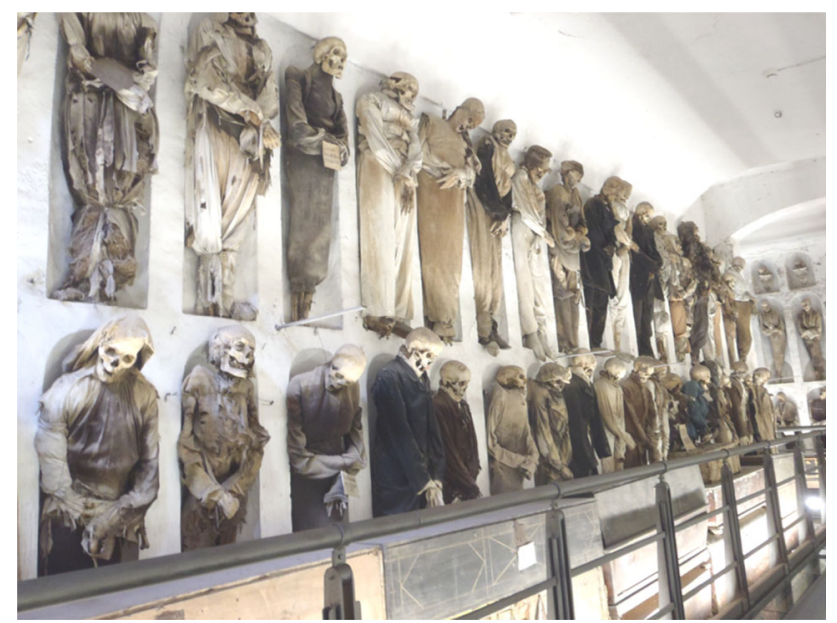

Fig. 1 Mummies displayed along the walls of the Capuchin Catacombs of Palermo, Italy (pictures: Sterflinger)

extreme hypersaline environment was present, yet interestingly some wall and tow samples recovered in the Capuchin Catacombs of Palermo (Italy) were sufficient to isolate moderately halophilic bacteria.

The Catacombs of Palermo contain over 1800 preserved bodies dating from the 16th to 20th centuries $\mathrm{AD}$, showing evidence of biodeterioration. Most of the mummies are positioned directly on the walls of the Catacombs (Fig. 1). Within the framework of the "Sicily Mummy Project", a sampling campaign performed at the Catacombs in 2010 revealed an extensive rosy discoloration of the Catacombs' walls, which were in direct contact with the surrounding soil. In some areas, water was migrating horizontally into the walls of the Catacombs (Fig. 2a), carrying with it soluble salts. Due to changes in physical parameters, salts from the solution precipitated at the exposed surface creating salt efflorescences (Amoroso and Fassina 1983), which appeared to be dispersed all over the walls (Fig. 2b). The crystallization of salts on the wall of the Catacombs has resulted in a destructive effect. Salts crystallized to different hydrates occupy a larger space and produce an additional pressure that has led to material loss and destruction due to cracking and detachment of the walls (Saiz-Jimenez and Laiz 2000). The detached material has accumulated on the surface of both coffins and mummies, producing further contamination of these artifacts (Fig. 2c). Moreover, the salt efflorescences deposited on the walls mimic the conditions found in extreme habitats, favoring the proliferation of halotolerant/halophilic microorganisms (Piñar et al. 2009). In a previous survey, an extensive microbiological and molecular investigation was performed at the Catacombs of Palermo (Piñar et al. 2013). Samples were taken from skin, muscle, hair, bone, stuffing materials, clothes and surrounding walls as well as from the air inside the Catacombs. The molecular techniques applied in that survey showed the dominance of halophilic species of the domains Bacteria and Archaea on the walls and, as a result of salt emanating from the walls, on some of the mummy-related materials. These microorganisms were thought to be responsible for the massive discoloration phenomena observed on the walls and stuffing materials. These results prompted further studies to focus on halophilic microorganisms that, in the past, were overlooked due to the use of unsuitable culture media with inadequate salt concentration, and/or the long incubation time required for the growth of this group of microorganisms under laboratory conditions (Piñar et al. 2001a).

Several studies have been published focusing on the formation of pigmented biofilms and the discoloration of various stone materials. They have shown that salt-attacked monuments, wall paintings and artworks represent a common habitat for extremely salt-tolerant and moderately halophilic microorganisms (Ettenauer et al. 2010; Imperi et al. 2007; Ortega-Morales et al. 2004, 2005; Piñar et al. 2001a, b, c, 2009, 2013; Ripka et al. 2006; Rölleke et al. 1996, 1998; SaizJimenez and Laiz 2000; Schabereiter-Gurtner et al. 2001). Microorganisms produce a wide variety of biogenic pigments such as chlorophyll, carotin, carotenoid, ruberin and melanin. The formation of orange to red pigments by halophilic microorganisms is due to the production of carotenoids. Carotenoids are isoprenoids containing a characteristic polyene chain of conjugated double bonds. The two general groups of pigments are the isoprenoid hydrocarbons (carotenes) and oxygenated derivatives (xanthophylls) (Köcher and Müller 2011). Carotenoids act to protect the cells against photooxidative damage (Köcher and Müller 2011; Oren 2009) as well as membrane stabilizers against chemical and/or salt stress (Köcher and Müller 2011). On salt-attacked objects, the inhabiting halophilic bacteria and haloarchaea usually form orange to pink or even violet stains (Fig. 3). The biogenic pigments are usually very stable on the materials even after the death of the causative microorganisms.

In this study, the cultivable fraction of the halophilic microflora inhabiting the walls and stuffing materials of the Catacombs of Palermo were investigated, to elucidate if they are involved in the discoloration phenomena observed on the different materials, and to clarify the potential biodegradative role of this peculiar microbiota in the further deterioration of the mummies and related materials. The objectives of this work were: (I) the isolation and molecular identification of the halophilic microbiota present on the walls and stuffing materials of the Catacombs, (II) the comparison of two different PCR-based methods for screening of the isolated strains, (III) to clarify the biological origin of the extensive rosy discoloration evidenced on the walls and other materials at the Catacombs and (IV) to test the biodegradative (proteolytic and cellulolytic) activities demonstrated by the isolated strains. 
Fig. 2 a Water migrating horizontally into the walls of the Catacombs. b Salt crusts of sodium chloride on the walls. c Detached salt contaminating other materials (pictures: Sterflinger)
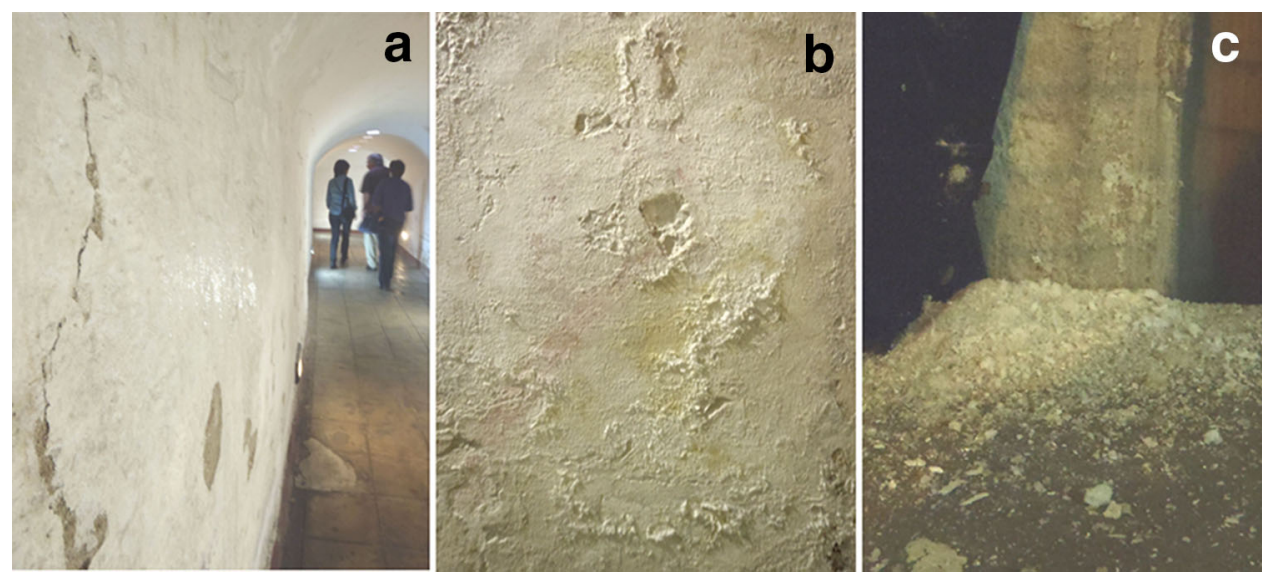

\section{Materials and methods}

\section{Sampling}

Three samples-W1: rosy discolored wall (Fig. 3a), W2: salt efflorescence with yellow discoloration (Fig. 3b) and PS: wall showing purple stains (Fig. 3c)—were collected and pooled from different areas of the walls of the Catacombs. In addition, sample $\mathrm{C} 3$, consisting of tow and straw used as stuffing material for the mummies and showing orange to rosy discoloration (Fig. 3d), was collected with sterile scalpels and forceps (Bayha $\mathrm{GmbH}$, Germany).

\section{Cultivation strategy}

Three different media were used for enrichment: Trypticase Soy Agar (TSA) supplemented with $\mathrm{NaCl}(3 \%)$ and $\mathrm{MgSO}_{4} \cdot 7 \mathrm{H}_{2} \mathrm{O}$ (2\%) (Laiz et al. 2009), Maintenance Medium (HMM, $10 \% \mathrm{NaCl}$ ) (Spring et al. 1996) and M2 medium $(20 \% \mathrm{NaCl})$ (Tomlinson and Hochstein 1976). Enrichments were conducted in $300 \mathrm{ml}$ Erlenmeyer flasks containing $30 \mathrm{ml}$ medium. To avoid fungal growth, media were supplemented with $50 \mathrm{mg} \mathrm{l}^{-1}$ cycloheximide (Sigma). Flasks were incubated aerobically at $28{ }^{\circ} \mathrm{C}$ by shaking at $180 \mathrm{rpm}$ (Thermo Scientific Equipment MaxQ 8000 , Germany). Over a total period of 4 weeks, weekly aliquots of $100 \mu \mathrm{l}$ enrichments were serial-diluted and plated onto the same solid media. Plates were incubated aerobically at room temperature and at $28{ }^{\circ} \mathrm{C}$ for 2-4 weeks, depending on the growth of the microorganisms. The cell morphology was examined on an Olympus SZX9 phase contrast microscope. Cells showing different morphology and appearance were transferred to new culture plates to obtain pure cultures. Pure isolates were cultivated in fresh media until exponential growth occurred, to be finally stored in $70 \%$ glycerol at $-80{ }^{\circ} \mathrm{C}$ for preservation.
Molecular screening of isolated microflora

Genomic DNAs were extracted according to the protocol provided by Ausubel et al. (1991). Bacterial strains were firstly selected by fluorescence ITS PCR (f-ITS) as described by Kraková et al. (2012). The internal transcribed spacer (ITS) between the 16S and 23S rRNA gene was amplified, and followed by separation of fluorescently labeled PCR products by capillary electrophoresis. Briefly, the PCR mixture contained $10 \mathrm{pmol}$ of L1: CAAGGCATCCACCGT (Jensen et al. 1993) and G17: FAMGTGAAGTCGTAACAAGG, FAM labeled primers (Kraková et al. 2012), $200 \mathrm{mmol}^{-1}$ dNTP, 1.5 U HotStarTaq plus DNA polymerase (Qiagen), 1x PCR buffer, and $6 \mu \mathrm{l}$ of template DNA in the total reaction volume of $25 \mu \mathrm{l}$. The temperature program consisted of the initial denaturation at $95{ }^{\circ} \mathrm{C}$ for $5 \mathrm{~min}, 35$ cycles $\left(95{ }^{\circ} \mathrm{C}\right.$ for $30 \mathrm{~s}, 54{ }^{\circ} \mathrm{C}$ for $30 \mathrm{~s}$, $72{ }^{\circ} \mathrm{C}$ for $1 \mathrm{~min}$ ) and a final polymerization at $72{ }^{\circ} \mathrm{C}$ for $8 \mathrm{~min}$. Resulting f-ITS products were separated on the automatic genetic analyzer ABI Prism 3100 Avant (Applied Biosystems, Foster City, CA, USA). DNA fragments were sized using the LIZ-600 DNA standard and GeneMapper 3.7 software (Applied Biosystems).

In addition, bacterial strains were subjected to Random Amplified Polymorphic DNA polymerase chain reaction (RAPD-PCR) analyses as described by Ripka et al. (2006). For RAPD analysis, the PCR was performed with three different primers (namely, primers D14216, D11344 and D14307), all of which were at least $17 \mathrm{nt}$ in length (Ripka et al. 2006). Primer concentrations of $12.5 \mathrm{pmol} \mathrm{ml}^{-1}$ were applied to the $1 \mathrm{x}$ diluted Master Mix (Promega). The PCR was carried out in 25 and $2.5 \mu \mathrm{l}$ of template was added. PCR reactions were executed in a MJ Research PTC-200 Peltier Thermal Cycler using PCR Master Mix (Promega, Mannheim, Germany). The cycling program was 4 cycles of $\left[94{ }^{\circ} \mathrm{C}, 5 \mathrm{~min} ; 4{ }^{\circ} \mathrm{C}, 5 \mathrm{~min}\right.$; and $72{ }^{\circ} \mathrm{C}, 5 \mathrm{~min}$; low stringency amplification], 30 cycles of $\left[94{ }^{\circ} \mathrm{C}, 1 \mathrm{~min}\right.$; 
Fig. 3 a Sample W1: rosy discolored wall. b Sample W2: salt efflorescence with yellowish discoloration. c Sample PS: wall showing purple stains. d Sample C3: stuffing material, showing orange to rosy discoloration (pictures: Sterflinger)
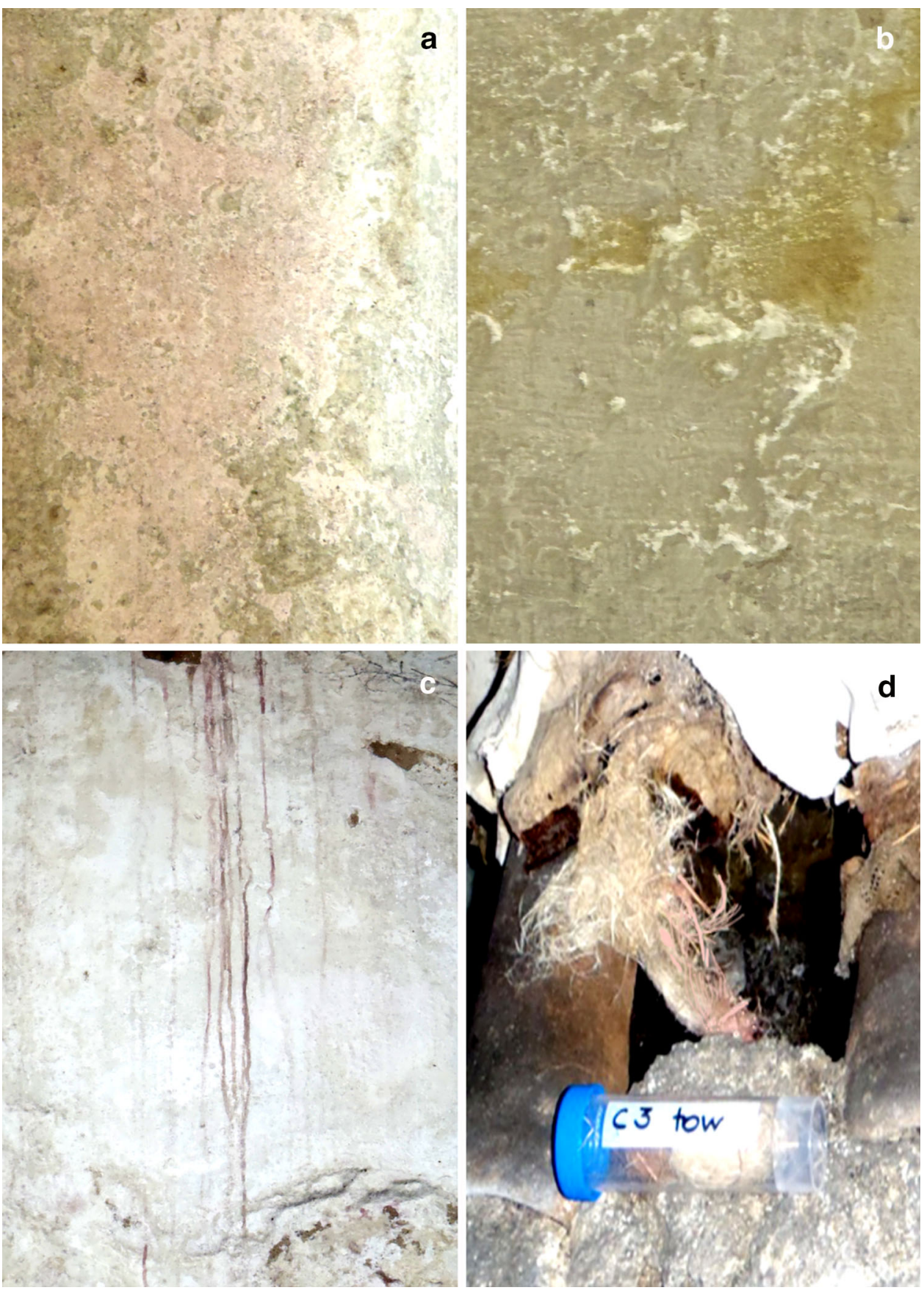

$55^{\circ} \mathrm{C}, 1 \mathrm{~min}$; and $72{ }^{\circ} \mathrm{C}, 2 \mathrm{~min}$; high stringency amplification] and a final elongation step for $10 \mathrm{~min}$ at $72{ }^{\circ} \mathrm{C}$ (Welsh and McClelland 1990). The whole reaction batches were run with $4 \mu$ l loading dye solution (Fermentas) in a $2 \%$ (w/v) agarose gel for $\sim 130-160 \mathrm{~min}$ at $70 \mathrm{~V}$, stained in an ethidium bromide solution $(1 \mathrm{mg} / \mathrm{ml}$; stock $10 \mathrm{mg}$ / $\mathrm{ml}$ ) for 30-45 min and visualized by a UVP documentation system (BioRad Transilluminator, Universal Hood; Mitsubishi P93D-printer). The GeneRulerTM 100 bp DNA ladder from Fermentas was used as a size marker.
16S rDNA sequencing and phylogenetic analyses

For sequencing analyses of bacterial isolates, $\sim 1200$ base pair 16S rDNA fragments were amplified using the forward primer 27f and the reverse primer 1492r (Lane 1991). $100 \mu \mathrm{l} \mathrm{PCR}$ reaction volumes separated into two tubes to 50 and $3 \mu$ of the extracted DNA were conducted. The thermocycling program used was as follows: 5 min denaturation at $95{ }^{\circ} \mathrm{C}$, followed by 30 cycles consisting of $1 \mathrm{~min}$ denaturation at $95{ }^{\circ} \mathrm{C}, 1 \mathrm{~min}$ primer annealing at $55^{\circ} \mathrm{C}$ and 2 min primer extension at $72{ }^{\circ} \mathrm{C}$, 
followed by a final extension step of $5 \mathrm{~min}$ at $72{ }^{\circ} \mathrm{C}$. The products obtained were purified using the QIAquick PCR Purification Kit (Qiagen) and analyzed by electrophoresis in $2 \%(\mathrm{w} / \mathrm{v})$ agarose gels. PCR products were externally sequenced by Sanger sequencing with a fleet of 16 ABI 3730xl (GATC Biotech, Germany). Comparative sequence analyses were performed by comparing pairwise insert sequences with those available in the online databases provided by the National Centre for Biotechnology Information using the BLAST search program (Altschul et al. 1997). The ribosomal sequences of the bacterial strains have been deposited in the EMBL nucleotide database under the accession numbers listed in Table 1.

\section{Biodegradative plate assays}

The proteolytic activity of the isolated microflora was tested by cultivation on gelatin agar plates (R2A-Gel) with different $\mathrm{NaCl}$ percentages $(3,10$ and $20 \%)$. The gelatin medium was prepared using R2A agar (Oxoid, Basingstoke, UK) plus 3 or $10 \%$ of $\mathrm{NaCl}$. This medium was autoclaved separately and then $0.4 \%$ of sterilized gelatin was added (Sigma-Aldrich, Germany) as well as an amount of a solution of $20 \% \mathrm{MgSO}_{4}$ autoclaved separately to reach into the agar with a final $\mathrm{MgSO}_{4}$ concentration of $2 \%$. The R2A agar with $20 \%$ of $\mathrm{NaCl}$ was prepared as the above media, but rather than the $\mathrm{MgSO}_{4}$ solution, $50 \mathrm{ml}$ of another solution, sterilized separately and composed by $40 \%$ of $\mathrm{MgCl}_{2} \times 7 \mathrm{H}_{2} \mathrm{O}, 4 \%$ of $\mathrm{KCl}$ and $0.4 \%$ of $\mathrm{CaCl}_{2} \times 2 \mathrm{H}_{2} \mathrm{O}$, were added into $950 \mathrm{ml}$ of agar medium. After the growth of the microorganisms, to have a better visualization of the hydrolysis zone, a $10 \%$ tannin solution was flooded on the agar plates (Saran et al. 2007). All proteolytic assays were performed in triplicate using 60-mm plates incubated at room temperature generally for 5-7 days.

The cellulolytic ability was checked using R2A agar with different salt concentrations (3,10 and 20\%) and prepared following the same procedures described above. Then the media were supplemented with $0.2 \%$ hydroxyethylcellulose containing $13.5 \% \quad(\mathrm{w} / \mathrm{w})$ of covalently linked Ostazin Brilliant Red H-3B (OBR-HEC, Institute of Chemistry, Slovak Academy of Sciences, Bratislava, Slovakia), which was autoclaved separately. On one agar plate, it was possible to test six strains at the same time, and a clear zone appeared around the cellulolytic microorganisms. The test was performed in triplicate and the plates were incubated at room temperature generally from 5 to 7 days.

\section{Results}

Isolation of bacterial strains

A total of 80 isolates differing in morphology and appearance could be cultivated from the four collected samples-16 strains (20\%) from sample W1, 13 strains from sample W2 (16.25\%), 27 strains from sample PS $(33.75 \%)$, and 24 strains from the stuffing material sample C3 $(30 \%)$. It is important to note that many of the isolated strains, especially those isolated from media containing higher $\mathrm{NaCl}$ concentrations, displayed a strong pigmentation ranging from yellow-orange to dark pink (Table 1).

Summarized over all 80 cultured strains, 25 isolates were derived from $3 \% \mathrm{NaCl}$ supplemented media (31.25\%), 27 strains from $10 \% \mathrm{NaCl}$ media $(33.75 \%)$, and 28 strains from $20 \% \mathrm{NaCl}$ media (35\%). To screen the bacterial isolates for sequencing and further characterization, a genotyping strategy was applied.

Bacterial selection and clustering

Two PCR-based techniques were used for the genotyping of the isolated strains. The f-ITS method is based on the amplification of the internal transcribed sequences between the bacterial $16 \mathrm{~S}$ and $23 \mathrm{~S}$ rDNA. RAPD-PCR uses arbitrarily chosen primers to prime DNA synthesis from pairs of sites with partial or complete matching and, as a result, DNA profiles are obtained based on variations in the entire bacterial genome. In this study, RAPD analyses were performed with three different primers as mentioned in the Methods section. Among the three tested primers, the $23 \mathrm{nt}$ primer D11344 proved to be the most discriminative (Fig. 4), originating RAPD-PCR profiles with higher band numbers. However, when using the other two primers (D14307 and D14216), not all isolates could be identified by type (data not shown).

Results derived from both PCR-based typing techniques, f-ITS and RAPD (using primer D11344), yielded the same conclusions, allowing the selection of 9 different fingerprints among the strains isolated from the $3 \% \mathrm{NaCl}$ medium, 5 of which came from wall samples and 4 from stuffing materials (Fig. 4a). The same was observed for the strains isolated from $10 \% \mathrm{NaCl}$. Both f-ITS and RAPD analyses allowed the identification of 18 different profiles, 12 of which were from wall samples and 6 were from stuffing materials, respectively (Fig. 4b). When the strains isolated from $20 \% \mathrm{NaCl}$ media were analyzed by both fingerprints PCR techniques, a certain discrepancy was evident: in fact, 12 and 7 different profiles were, respectively, produced by RAPD (Fig. 4c) and f-ITS. The main difference concerned the RAPD clusters including the isolates PS13, PS15, PS17, PS18, PS19a (cluster 1); PS20 (cluster 2), PS21 (cluster 3); PS22, PS23 (cluster 4); PS24 (cluster 5), which were grouped by f-ITS in a unique cluster $\left(\mathrm{VI}_{10}\right)$. These resulted in the same cluster of the strain W2-5 isolated on the $10 \% \mathrm{NaCl}$ medium (see Table 1). The strains W1-15 and W1-16, differentiated by RAPD, were also included in the same f-ITS cluster $\left(\mathrm{I}_{20}\right)$. 
Table 1 Grouping according to f-ITS and RAPD-PCR, phenotypic characteristics, phylogenetic classification and biodegradative tests of the isolated bacterial strains

\begin{tabular}{|c|c|c|c|c|c|c|c|c|}
\hline $\begin{array}{l}{[\mathrm{NaCl}]} \\
(\%)\end{array}$ & f-ITS profiles (bp) & $\begin{array}{l}\text { Strains grouped by } \\
\text { RAPD }\end{array}$ & Phenotype & Closest phylogenetic relative & $\begin{array}{l}\text { Similarity } \\
(\%)\end{array}$ & $\begin{array}{l}\text { Accession } \\
\text { Nr. }\end{array}$ & $\begin{array}{l}\text { Proteolytic } \\
\text { test }\end{array}$ & $\begin{array}{l}\text { Cellulolytic } \\
\text { test }\end{array}$ \\
\hline \multicolumn{9}{|c|}{ Sample W1—rosy discolored wall } \\
\hline 3 & $\mathrm{I}_{3}:(670,760)$ & $\begin{array}{c}\text { W1-1a, W1-1b, } \\
\text { W1-3, W1-4, } \\
\text { W1-5, W1-6 }\end{array}$ & $\begin{array}{l}\text { Salmon- } \\
\text { yellowish } \\
\text { colonies }\end{array}$ & $\begin{array}{l}\text { Idiomarina sp. [KC753341, } \\
\text { JF521499, AB167046] }\end{array}$ & 99.0 & KJ145754 & + & n.d. \\
\hline \multirow[t]{5}{*}{10} & $\begin{array}{l}\mathrm{I}_{10}:(261,283,293, \\
\quad 308,402,405,457, \\
\quad 463)\end{array}$ & W1-7, W1-8 & $\begin{array}{l}\text { White, bright } \\
\text { colonies }\end{array}$ & $\begin{array}{l}\text { Oceanobacillus oncorhynchi } \\
\text { [JN409467, NR_042257] }\end{array}$ & 99.0 & KJ145755 & - & n.d. \\
\hline & $\mathrm{II}_{10}:(365,449,633)$ & $W 1-9, \mathrm{~W} 1-14$ & $\begin{array}{l}\text { Salmon, bright } \\
\text { colonies }\end{array}$ & $\begin{array}{l}\text { Virgibacillus sp. [EU277749, } \\
\text { KC013356] }\end{array}$ & 98.0 & KJ145756 & ++ & n.d. \\
\hline & $\begin{array}{l}\mathrm{III}_{10}:(600,651,657, \\
\quad 709,726)\end{array}$ & $W 1-10, \mathrm{~W} 1-12$ & $\begin{array}{l}\text { Salmon- } \\
\text { yellowish } \\
\text { colonies }\end{array}$ & $\begin{array}{l}\text { Idiomarina sp. [JF521499, } \\
\text { AB526349, FJ746576] }\end{array}$ & 99.0 & KJ145757 & w.g. & n.d. \\
\hline & $\begin{array}{l}\mathrm{IV}_{10}:(597,654,656 \\
\quad 725)\end{array}$ & $W 1-11$ & $\begin{array}{l}\text { Beige-salmon } \\
\text { colonies }\end{array}$ & $\begin{array}{l}\text { Virgibacillus picturae } \\
\text { [AJ276808] }\end{array}$ & 99.0 & KJ145758 & + & n.d. \\
\hline & $\begin{array}{l}\mathrm{V}_{10}:(365,590,629 \\
637,808)\end{array}$ & $W 1-13$ & $\begin{array}{l}\text { Yellow, bright } \\
\text { colonies }\end{array}$ & $\begin{array}{l}\text { Oceanobacillus sp. } \\
\text { [FJ424491, NR_028952] }\end{array}$ & 100 & KJ145759 & + & n.d. \\
\hline \multirow[t]{2}{*}{20} & \multirow[t]{2}{*}{$\mathrm{I}_{20}:(387,411)$} & $W 1-15$ & Beige colonies & $\begin{array}{l}\text { Halobacillus virgiliensis } \\
\text { [AM161501, AM161499] }\end{array}$ & 99.0 & KJ145760 & - & n.d. \\
\hline & & $W 1-16$ & Pink colonies & $\begin{array}{l}\text { Halobacillus virgiliensis } \\
\text { [AM161501, AM161499] }\end{array}$ & 99.0 & KJ145761 & - & n.d. \\
\hline \multicolumn{9}{|c|}{ Sample W2-wall showing salt efflorescence with yellow discoloration } \\
\hline \multirow[t]{2}{*}{3} & $\begin{array}{l}\mathrm{II}_{3}:(310,343,431, \\
\quad 435)\end{array}$ & $\begin{array}{l}\text { W2-1a, W2-1b, } \\
\text { W2-3, W2-4a, } \\
\text { W2-4b }\end{array}$ & $\begin{array}{l}\text { Beige big } \\
\text { colonies }\end{array}$ & $\begin{array}{l}\text { Bacillus aryabhattai } \\
\text { [KF208483] }\end{array}$ & 99.0 & KJ145762 & + & n.d. \\
\hline & $\mathrm{III}_{3}:(232)$ & $W 2-2$ & $\begin{array}{l}\text { Beige, small } \\
\text { colonies }\end{array}$ & $\begin{array}{l}\text { Lysinibacillus sp. [KF208480, } \\
\text { KF788075] }\end{array}$ & 99.0 & KJ145763 & - & n.d. \\
\hline \multirow[t]{2}{*}{10} & $\begin{array}{l}\mathrm{VI}_{10}:(280,299,301, \\
340,526,543)\end{array}$ & $W 2-5$ & $\begin{array}{l}\text { Beige- } \\
\text { yellowish } \\
\text { colonies }\end{array}$ & $\begin{array}{l}\text { Halobacillus hunanensis } \\
\text { [FJ425898] } \\
\text { Halobacillus naozhouensis, } \\
\text { [HG515391] }\end{array}$ & 99.0 & KJ145764 & + & n.d. \\
\hline & $\begin{array}{l}\mathrm{VII}_{10}:(480,649,689, \\
811)\end{array}$ & $W 2-6, \mathrm{~W} 2-7$ & $\begin{array}{l}\text { Salmon- } \\
\text { yellowish, } \\
\text { bright } \\
\text { colonies }\end{array}$ & $\begin{array}{l}\text { Idiomarina sp. [KC753341, } \\
\text { HE586864, JF521499] }\end{array}$ & 99.0 & KJ145765 & w.g. & n.d. \\
\hline 20 & $\mathrm{II}_{20}:(386,411)$ & $\begin{array}{l}\text { W2-8, W2-9, W2- } \\
10, \mathrm{~W} 2-11\end{array}$ & $\begin{array}{l}\text { Yellow- } \\
\text { orange } \\
\text { colonies }\end{array}$ & $\begin{array}{l}\text { Marinococcus sp. } \\
\text { [HG515394, AY987847] }\end{array}$ & 99.0 & KJ145766 & - & n.d. \\
\hline \multicolumn{9}{|c|}{ Sample PS—wall showing purple stains } \\
\hline \multirow[t]{2}{*}{3} & $\mathrm{IV}_{3}:(215,232,457)$ & $\begin{array}{l}\text { PS1a, PS1b, PS3a, } \\
\text { PS3b, PS5 }\end{array}$ & Beige colonies & $\begin{array}{l}\text { Bacillus sp. [JN230359, } \\
\text { JN717163, JN082261] }\end{array}$ & 99.0 & KJ145767 & +++ & n.d. \\
\hline & $\mathrm{V}_{3}:(636,680,764)$ & PS4, PS6 & $\begin{array}{l}\text { Yellow, bright } \\
\text { colonies }\end{array}$ & $\begin{array}{l}\text { Arthrobacter protophormiae } \\
\text { [NR_026195, JX007987, } \\
\text { EU086815] }\end{array}$ & 99.0 & KJ145768 & +++ & n.d. \\
\hline \multirow[t]{5}{*}{10} & $\begin{array}{l}\mathrm{VIII}_{10}:(628,669, \\
761)\end{array}$ & $P S 7$ & $\begin{array}{l}\text { Salmon- } \\
\text { orange, } \\
\text { bright } \\
\text { colonies }\end{array}$ & $\begin{array}{l}\text { Halomonas sp. [HM587244, } \\
\text { EU308349] }\end{array}$ & 98.0 & KJ145769 & - & n.d. \\
\hline & $\mathrm{IX}_{10}:(694,796)$ & $P S 7 b$ & $\begin{array}{l}\text { Salmon- } \\
\text { yellowish, } \\
\text { bright } \\
\text { colonies }\end{array}$ & $\begin{array}{l}\text { Oceanobacillus picturae } \\
\text { [AB489113, EF512727, } \\
\text { EF512732] }\end{array}$ & 99.0 & KJ145770 & + & n.d. \\
\hline & $\begin{array}{l}\mathrm{X}_{10}:(662,669,742, \\
\quad 754,811)\end{array}$ & $P S 8$ & $\begin{array}{r}\text { Beige, big } \\
\text { colonies }\end{array}$ & $\begin{array}{l}\text { Bacillus sp. [FJ373031, } \\
\text { AJ315068, Q030919] }\end{array}$ & 99.0 & KJ145771 & ++ & n.d. \\
\hline & $\mathrm{XI}_{10}:(651,699,730)$ & $P S 9$ & Beige colonies & $\begin{array}{l}\text { Halomonas sp. [KF682368, } \\
\text { KC884689, JQ716247] }\end{array}$ & 99.0 & KJ145772 & w.g. & n.d. \\
\hline & $\begin{array}{l}\mathrm{XII}_{10}:(689,693,794, \\
812)\end{array}$ & PS10, PS11 & $\begin{array}{l}\text { Salmon- } \\
\text { orange } \\
\text { colonies }\end{array}$ & $\begin{array}{l}\text { Bacillus sp. [HQ699497, } \\
\text { JQ716212, JF411285] }\end{array}$ & 99.0 & KJ145773 & +++ & n.d. \\
\hline
\end{tabular}


Table 1 continued

\begin{tabular}{|c|c|c|c|c|c|c|c|c|}
\hline $\begin{array}{l}{[\mathrm{NaCl}]} \\
(\%)\end{array}$ & f-ITS profiles (bp) & $\begin{array}{l}\text { Strains grouped by } \\
\text { RAPD }\end{array}$ & Phenotype & Closest phylogenetic relative & $\begin{array}{l}\text { Similarity } \\
(\%)\end{array}$ & $\begin{array}{l}\text { Accession } \\
\mathrm{Nr} \text {. }\end{array}$ & $\begin{array}{l}\text { Proteolytic } \\
\text { test }\end{array}$ & $\begin{array}{l}\text { Cellulolytic } \\
\text { test }\end{array}$ \\
\hline \multirow[t]{12}{*}{20} & $\begin{array}{l}\mathrm{III}_{20}:(331,383,386, \\
411,421,453,483, \\
597)\end{array}$ & PS12, PS14, & $\begin{array}{l}\text { Beige, small } \\
\text { colonies }\end{array}$ & $\begin{array}{l}\text { Oceanobacillus iheyensis } \\
\text { [BA000028] }\end{array}$ & 99.0 & KJ145774 & - & n.d. \\
\hline & $\begin{array}{l}\mathrm{IV}_{20}:(295,319,357 \\
\quad 547,562)\end{array}$ & PS16 & Beige colonies & $\begin{array}{l}\text { Halobacillus styriensis } \\
\text { [AM161506, AM161507] }\end{array}$ & 99.0 & KJ145775 & + & n.d. \\
\hline & \multirow[t]{9}{*}{$\begin{array}{l}\mathrm{VI}_{10}:(280,299,301 \\
340,526,543)\end{array}$} & \multirow[t]{2}{*}{$\begin{array}{l}\text { PS13, PS15, PS17, } \\
\text { PS18, PS19a }\end{array}$} & \multirow[t]{2}{*}{$\begin{array}{r}\text { Dark pink } \\
\text { colonies }\end{array}$} & \multirow{2}{*}{$\begin{array}{l}\text { Halobacillus hunanensis } \\
\text { [FJ425898] } \\
\text { Halobacillus naozhouensis, } \\
\text { [HG515391] }\end{array}$} & $\begin{array}{l}99.0 \\
990\end{array}$ & \multirow[t]{2}{*}{ KJ145776 } & \multirow[t]{2}{*}{+} & \multirow[t]{2}{*}{ n.d. } \\
\hline & & & & & & & & \\
\hline & & \multirow[t]{2}{*}{ PS20 } & \multirow[t]{2}{*}{$\begin{array}{r}\text { Dark pink } \\
\text { colonies }\end{array}$} & $\begin{array}{l}\text { Halobacillus hunanensis } \\
\text { [FJ425898] }\end{array}$ & 99.0 & \multirow[t]{2}{*}{ KJ145777 } & \multirow[t]{2}{*}{+} & \multirow[t]{2}{*}{ n.d } \\
\hline & & & & $\begin{array}{l}\text { Halobacillus naozhouensis, } \\
\text { [HG515391] }\end{array}$ & & & & \\
\hline & & \multirow[t]{2}{*}{$P S 21$} & \multirow{2}{*}{$\begin{array}{l}\text { Beige- } \\
\text { yellowish } \\
\text { colonies }\end{array}$} & $\begin{array}{l}\text { Halobacillus hunanensis } \\
\text { [FJ425898] }\end{array}$ & \multirow[t]{2}{*}{99.0} & \multirow[t]{2}{*}{ KJ145778 } & \multirow[t]{2}{*}{+} & \multirow[t]{2}{*}{ n.d. } \\
\hline & & & & $\begin{array}{l}\text { Halobacillus naozhouensis, } \\
\text { [HG515391] }\end{array}$ & & & & \\
\hline & & $P S 22, \mathrm{PS} 23$ & $\begin{array}{l}\text { Salmon } \\
\text { colonies }\end{array}$ & Halobacillus sp. [AB695093] & 99.0 & KJ145779 & - & n.d. \\
\hline & & PS24 & $\begin{array}{r}\text { Dark pink } \\
\text { colonies }\end{array}$ & $\begin{array}{l}\text { Halobacillus hunanensis } \\
\text { [FJ425898] }\end{array}$ & 99.0 & KJ145780 & + & n.d \\
\hline & & & & $\begin{array}{l}\text { Halobacillus naozhouensis, } \\
\text { [HG515391] }\end{array}$ & & & & \\
\hline & $\begin{array}{l}\mathrm{V}_{20}:(347,367,371, \\
377,399,450,456, \\
557,564)\end{array}$ & $P S 19 b$ & $\begin{array}{l}\text { Beige, small } \\
\text { colonies }\end{array}$ & $\begin{array}{l}\text { Staphylococcus equorum } \\
\text { [KF439737, KF439739, } \\
\text { KC844770] }\end{array}$ & 99.0 & KJ145781 & - & n.d. \\
\hline \multicolumn{9}{|c|}{ Sample C3-stuffing material showing orange to rosy discoloration } \\
\hline \multirow[t]{4}{*}{3} & $\begin{array}{l}\mathrm{VI}_{3}:(246,266,299 \\
\quad 455,466)\end{array}$ & $C 3-1 a, \mathrm{C} 3-1 \mathrm{~b}$ & $\begin{array}{l}\text { Beige, big } \\
\text { mucous } \\
\text { colonies }\end{array}$ & $\begin{array}{l}\text { Bacillus endophyticus } \\
\text { [KF254667, HQ844498, } \\
\text { HM753612] }\end{array}$ & 99.0 & KJ145782 & + & - \\
\hline & $\mathrm{VII}_{3}:(636,691,783)$ & C3-2 & $\begin{array}{l}\text { Yellow, bright } \\
\text { colonies }\end{array}$ & $\begin{array}{l}\text { Halomonas sp. [KF682368, } \\
\text { KC884689, JQ716248] }\end{array}$ & 99.0 & KJ145783 & - & - \\
\hline & $\begin{array}{l}\mathrm{VIII}_{3}:(266,592,668, \\
755)\end{array}$ & $C 3-3$ & $\begin{array}{l}\text { Salmon, bright } \\
\text { colonies }\end{array}$ & $\begin{array}{l}\text { Halomonas sp. [EF512731, } \\
\text { EF512710] }\end{array}$ & 99.0 & KJ145784 & - & - \\
\hline & $\mathrm{IX}_{3}:(602,657,725)$ & $C 3-4, \mathrm{C} 3-5$ & $\begin{array}{l}\text { White, bright } \\
\text { colonies }\end{array}$ & $\begin{array}{l}\text { Staphylococcus sp. } \\
\text { [FN994187, FJ386519] }\end{array}$ & 99.0 & KJ145785 & - & - \\
\hline \multirow[t]{7}{*}{10} & $\begin{array}{l}\mathrm{XIII}_{10}:(693,730, \\
797)\end{array}$ & C3-6, C3-11 & $\begin{array}{r}\text { Beige, big } \\
\text { colonies }\end{array}$ & $\begin{array}{l}\text { Staphylococcus equorum } \\
\text { [KF439737, KF439739, } \\
\text { KC844770] }\end{array}$ & 99.0 & KJ145786 & - & + \\
\hline & $\begin{array}{l}\mathrm{XIV}_{10}:(689,692, \\
795)\end{array}$ & C3-7, C3-8 & $\begin{array}{l}\text { Beige, small } \\
\text { colonies }\end{array}$ & $\begin{array}{l}\text { Chromohalobacter } \\
\text { nigrandesensis } \\
\text { [NR_042011] }\end{array}$ & 99.0 & KJ145787 & - & + \\
\hline & $\begin{array}{l}\mathrm{XV}_{10}:(420,454,534, \\
550)\end{array}$ & C3-9 & $\begin{array}{l}\text { Beige-salmon } \\
\text { colonies }\end{array}$ & $\begin{array}{l}\text { Halomonas sp. [EU440966, } \\
\text { DQ659441] }\end{array}$ & 99.0 & KJ145788 & - & - \\
\hline & $\begin{array}{l}\mathrm{XVI}_{10}:(406,454, \\
551)\end{array}$ & C3-10 & $\begin{array}{l}\text { Yellow } \\
\text { colonies }\end{array}$ & $\begin{array}{l}\text { Halomonas sp. [EU088257, } \\
\text { FN257742, JQ716247] }\end{array}$ & 98.0 & KJ145789 & - & + \\
\hline & $\begin{array}{l}\mathrm{XVII}_{10}:(274,302, \\
\quad 381,400,418,671)\end{array}$ & $\begin{array}{l}\text { C3-12, C3-14, C3- } \\
15\end{array}$ & $\begin{array}{l}\text { Intense orange } \\
\text { colonies }\end{array}$ & $\begin{array}{l}\text { Uncultured bacterium } \\
\text { microbiome [HM292641] }\end{array}$ & $\begin{array}{l}98.0 \\
97.0\end{array}$ & KJ145790 & - & $-/+$ \\
\hline & & & & $\begin{array}{l}\text { Brevibacterium permese } \\
\quad \text { [NR_025732] }\end{array}$ & & & & \\
\hline & $\mathrm{XVIII}_{10}:(386,411)$ & $C 3-13$ & $\begin{array}{l}\text { Yellow } \\
\text { colonies }\end{array}$ & $\begin{array}{l}\text { Virgibacillus } \\
\text { halodenitrificans } \\
\text { [NR_042967, AB697708, } \\
\text { AB697710] }\end{array}$ & 99.0 & KJ145791 & + & - \\
\hline
\end{tabular}


Table 1 continued

\begin{tabular}{|c|c|c|c|c|c|c|c|c|}
\hline $\begin{array}{l}{[\mathrm{NaCl}]} \\
(\%)\end{array}$ & f-ITS profiles (bp) & $\begin{array}{l}\text { Strains grouped by } \\
\text { RAPD }\end{array}$ & Phenotype & Closest phylogenetic relative & $\begin{array}{l}\text { Similarity } \\
(\%)\end{array}$ & $\begin{array}{l}\text { Accession } \\
\text { Nr. }\end{array}$ & $\begin{array}{l}\text { Proteolytic } \\
\text { test }\end{array}$ & $\begin{array}{l}\text { Cellulolytic } \\
\text { test }\end{array}$ \\
\hline \multirow[t]{2}{*}{20} & $\mathrm{VI}_{20}:(250,781)$ & $\begin{array}{l}\text { C3-16, C3-17, C3- } \\
18, \text { C3-19 }\end{array}$ & $\begin{array}{l}\text { Beige, small } \\
\text { colonies }\end{array}$ & $\begin{array}{c}\text { Chromohalobacter } \\
\text { nigrandesensis } \\
\text { [NR_042011] }\end{array}$ & 99.0 & KJ145792 & - & + \\
\hline & $\begin{array}{l}\mathrm{VII}_{20}:(247,298,339, \\
\quad 412,526)\end{array}$ & $\begin{array}{l}\text { C3-20, C3-21, C3- } \\
22, \text { C3-23 }\end{array}$ & $\begin{array}{r}\text { Beige, big } \\
\text { colonies }\end{array}$ & $\begin{array}{l}\text { Nesterenkonia halobia } \\
\text { [NR_026197] } \\
\text { Nesterenkonia halophila } \\
\text { [NR_043205] }\end{array}$ & $\begin{array}{l}99.0 \\
99.0\end{array}$ & KJ145793 & - & + \\
\hline
\end{tabular}

n.d. not determined, w.g. weak growth, + positive reaction, ++ strong positive reaction, +++ very strong positive reaction f-ITS profiles: $\mathrm{I}_{3}-\mathrm{IX}_{3} ; \mathrm{I}_{10}-\mathrm{XVIII}{ }_{10} ; \mathrm{I}_{20}-\mathrm{VII}_{20}$, the size, in bp, of the amplified fragments is shown in brackets Strains marked in italics were subjected to sequencing and phylogenetic analyses

Fig. 4 RAPD-PCR patterns of representative strains isolated from a $3 \% \mathrm{NaCl}, \mathbf{b} 10 \% \mathrm{NaCl}$, and c $20 \% \mathrm{NaCl}$ media. The number of lanes indicates the number of the strains. Lanes $M$ $1 \mathrm{~kb}$ ladder (Fermentas)
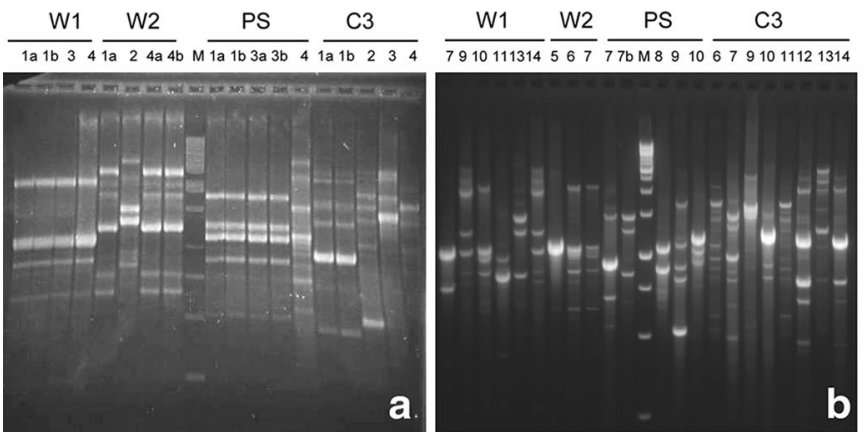

$\frac{W 1}{1516} \frac{W 2}{810} \frac{P S}{141618 \text { 19a M19b } 20212224} \frac{C 3}{162023}$

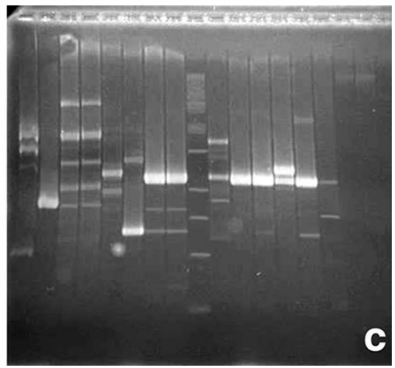

Finally, the strains C3-20 and C3-23, non-typeable by RAPD, produced the same f-ITS profile $\left(\mathrm{VII}_{20}\right)$ together with the isolates $\mathrm{C} 3-21$ and $\mathrm{C} 3-22$.

One interesting point was the case of different Staphylococcus strains, i.e., S. equorum (strains PS19b, C3-4, C35, and C3-6, C3-11) isolated from different media, which were separated by RAPD and f-ITS $\left(\mathrm{V}_{20}, \mathrm{IX}_{3}\right.$, and XIII $\left.{ }_{10}\right)$ in three different clusters corresponding to diverse salt concentrations. The data regarding the clustering of all isolated strains are showed in Table 1.

Phylogenetic identification of selected bacterial strains

One representative strain of each RAPD cluster was selected for identification by $16 \mathrm{~S}$ rDNA sequencing. The isolate C3-20, not typeable by RAPD analyses (see Fig. 4c), was also selected for identification. The phylogenetic identification of the selected strains obtained by comparison of sequences derived from the isolated strains with sequences of known bacteria in the EMBL database using the search tools FASTA and BLAST is summarized in Table 1.

Similarity values with sequences from the EMBL database ranged from 98 to $100 \%$. Most of the isolates were affiliated with cultured bacterial strains, but the strain C3-12 was mostly related to an uncultured cloned sequence from the microbiome, and with less similarity (97\%) with cultured species of the genus Brevibacterium. Results from
16S rDNA sequence analysis revealed that all 80 strains were affiliated with species of 13 genera within three phyla: Firmicutes, of the order Bacillales (number of isolates, $n=49$, representing $61.25 \%$ of all isolated strains), Proteobacteria, of the Gamma-class $(n=22,27.5 \%)$, and Actinobacteria $(n=9,11.25 \%)$.

Within the Firmicutes phylum, a total of seven different genera were identified, with the genera Bacillus and Halobacillus being the two most abundant (representing 18.75 and $17.5 \%$ of all isolated strains, respectively). The Oceanobacillus genus accounted for $7.5 \%$ of the total strains and the Staphylococcus genus for $6.25 \%$. In addition, the genera Virgibacillus and Marinococcus accounted for $5 \%$ each of the total strains, while finally, the genus Lysinibacillus accounted for $1.25 \%$ of the total strains. Within the Gammaproteobacteria, three different genera were identified, namely the genera Idiomarina $(12.5 \%$ of total strains), Halomonas and Chromohalobacter (each $7.5 \%)$. Finally, three genera showed to be affiliated with the phylum Actinobacteria, namely the genus Nesterenkonia (5\% of strains), uncultured strains most related to the genus Brevibacterium $(3.75 \%)$ and the genus Arthrobacter (2.5\%).

\section{Biodegradative characterization}

The 80 isolated bacterial strains were screened for their proteolytic activity and, in addition, those strains isolated 
from stuffing materials were tested for their cellulolytic properties.

Many of the bacterial strains isolated from wall materials displayed proteolytic activities. All strains related to species of the genera Bacillus and Virgibacillus, also isolated from stuffing materials, showed a strong proteolytic activity (Table 1). The genus Oceanobacillus showed a different behavior depending on the species detected. Those strains most related to $O$. oncorhynchi and $O$. iheyensis showed negative results and those related to Oceanobacillus sp. and $O$. picturae showed positive results in the proteolytic test. The same was observed for the genus Halobacillus. Strains most related to $H$. virgiliensis showed no proteolytic activities and those most related to $H$. styriensis and $H$. hunanensis showed positive results. The rest of the strains related to members of the Firmicutes, affiliating to species of the genera Lysinibacillus, Marinococcus and Staphylococcus, showed no proteolytic activities (Table 1).

Within the Gammaproteobacteria, strains related to Idiomarina sp., those isolated from wall samples W1 and $\mathrm{W} 2$, displayed proteolytic activities only when the bacteria were grown in the $3 \% \mathrm{NaCl}$ medium, but not in the $10 \%$ $\mathrm{NaCl}$ medium. However, the reason behind this could be the very weak growth of these strains in the latter culture medium (Table 1). Strains related to species of the genera Halomonas and Chromohalobacter, mainly isolated from stuffing materials, showed no proteolytic activities.

Within the Actinobacteria, strains related to Arthrobacter protophormiae, isolated only from wall sample PS, showed a strong proteolytic activity. In contrast, strains mostly related to uncultured clones from the microbiome and to Nesterenkonia halobia, only isolated from stuffing materials, showed negative results in the proteolytic test.

The cellulose-rich content of the materials used as stuffing for the mummies, tow and straw, prompted the further cellulolytic test on the strains isolated from these materials. Strains related to Chromohalobacter sp. (C. nigrandesensis) and to Nesterenkonia sp. (N. halobia and $N$. halophila) all showed cellulolytic activities. Strains related to Staphylococcus sp. and to Halomonas sp. showed a variation depending on the strains, some of them being positive and some of them negative in the cellulolytic test (Table 1). The same was observed for the strains related to an uncultured clone from the microbiome.

\section{Discussion}

Cultivation analyses

It is well known that the use of standard cultivation techniques enables only a small proportion of the total inhabiting bacterial population to be cultivated (Amann et al. 1995; Ward et al. 1990). When dealing with the isolation of halophilic microorganisms, the preparation and use of hypersaline media reveal special challenges unique to high salinities, as well as the same concerns regarding any microbial culture system (Schneegurt 2012). Therefore, three different culture media that were previously used with success for the isolation of moderately halophilic microorganisms were applied in this study (Laiz et al. 2009; Spring et al. 1996; Tomlinson and Hochstein 1976). As a result, 80 halophilic bacteria were isolated from three wall samples showing orange to rosy and even purple discoloration as well as salt efflorescences and from the tow and straw used as the stuffing material for the mummies displayed in the Catacombs. Moderately halophilic bacteria grow optimally in media containing 3-15\% (w/v) salt, but they can also grow at as high concentrations as $25 \%$ (Ventosa et al. 1998). This is the case of the species of Idiomarina, Halomonas, Oceanobacillus, Virgibacillus, Marinococcus and Chromohalobacter (Gurtner et al. 2000; Heyrman and Swings 2001; Heyrman et al. 2002, 2003; Ivanova et al. 2000; Lu et al. 2001; Maturrano et al. 2006; Peng et al. 2009; Prado et al. 2006; Ripka et al. 2006; Romano et al. 2006; Wang et al. 2008; Yoon et al. 2004) and some species of the genera Bacillus and Staphylococcus (El-Rahman et al. 2002; Heyrman and Swings 2001; Jeong et al. 2013) that showed to be the closest relatives of the strains isolated in this study. Interestingly, the Nesterenkonia species were only isolated in media containing $20 \% \mathrm{NaCl}$, in spite of the fact that they are considered to be moderately halophilic ( $\mathrm{Li}$ et al. 2008). A similar behavior was observed for the species of the Halobacillus genus, which were mainly isolated in media containing $20 \% \mathrm{NaCl}$ and could be isolated in the medium containing $10 \% \mathrm{NaCl}$ only in the case of sample W2.

Comparison of the two PCR-based typing methods for screening of the isolated strains

The two PCR-based molecular methods used for screening the isolated bacteria, f-ITS and RAPD, allowed differentiation between the 80 isolated strains in an early selection step. This previous screening facilitates microbiologists to choose among several microorganisms possessing similar morphology after the isolation step. The f-ITS-PCR has already been tested for the screening of microorganisms in different environments (Bućková et al. 2013; Kraková et al. 2012; Pangallo et al. 2008; 2009), and its usefulness in selecting isolated bacteria was reconfirmed in this study. However, when comparing f-ITS-PCR for genotyping of bacterial strains with RAPD analysis, it turned out that the latest PCR-based method possessed a higher discriminatory power. The discrepancy was evident mainly for several 
Halobacillus hunanensis strains which were included in only one cluster $\left(\mathrm{VI}_{10}\right)$ by f-ITS, while RAPD analyses divided them among 5 different groups. This can be due to the fact that the f-ITS-PCR is only able to discriminate genetic variations occurring within the internal transcribed sequences between the bacterial $16 \mathrm{~S}$ and $23 \mathrm{~S}$ rDNA analyzed. In contrast, RAPD-PCR uses an oligonucleotide of an arbitrarily chosen sequence to prime DNA synthesis from pairs of sites with which it partially or completely matches. The DNA profiles obtained allow discrimination at the subspecies level based on the DNA diversity in the entire bacterial genome, offering a broad spectrum of genetic variation (Welsh and McClelland 1990; Williams et al. 1990). This study further supports the fact that RAPD-PCR profiling reveals more detailed results and subclassifies more strains at the species level (Ettenauer et al. 2010; Ripka et al. 2006).

Nevertheless, it is worth noting that results derived from RAPD-PCR analyses are strongly influenced by the primer used. In this study, RAPD profiles were obtained and compared by the independent use of three different primers, as mentioned in the Methods section. The three primers were at least $17 \mathrm{nt}$ and contained 44-55\% GC. The differences in their GC content may affect annealing behavior (Power 1996). Primer D11344, at a concentration of 12.5 pmol per PCR, showed the most informative RAPDPCR profiles (higher band numbers), confirming the results of previous studies (Ettenauer et al. 2010; Ripka et al. 2006). When using the other primers (D14307 and D14216) not all isolates proved to be typeable.

Those strains isolated at different $\mathrm{NaCl}$ concentrations and showing different RAPD profiles were subjected to sequencing and the results obtained were compared with sequencing results previously obtained from the same samples, when molecular analyses were applied to elucidate their biodiversity (Piñar et al. 2013).

Comparison of the cultivable and non-cultivable fraction of the microbiota present on wall samples and stuffing materials

As previously reported in other studies (Donachie et al. 2007; Laiz et al. 2003; López-Miras et al. 2013a, b), culture-dependent and -independent methods yielded different results from the same sample when the results obtained in this study and those from our previous molecular survey at the Catacombs (Piñar et al. 2013) were compared. The order Bacillales of the phylum Firmicutes proved to be dominant on the enrichment cultures of the three wall samples, representing $50,84.6$ and $85.2 \%$ of the strains isolated from samples $\mathrm{W} 1, \mathrm{~W} 2$ and PS, respectively. On the stuffing material (sample $\mathrm{C} 3$ ), it was represented by $29.2 \%$ of the isolated strains. Nevertheless, members of this order were not detected by molecular techniques on sample PS and C3, but they were on samples W1 and W2, and with a lower proportion in the clone libraries (21 and $28.3 \%$ of clones for W1 and W2, respectively) (Piñar et al. 2013). Members of the phylum Proteobacteria (of the Gamma-class) were isolated from all wall samples as well as from the stuffing material, contributing 50, 15.4 and $7.4 \%$ of the strains isolated from wall samples $\mathrm{W} 1, \mathrm{~W} 2$ and PS, respectively, and $41.6 \%$ of the strains isolated from sample C3. However, the cultivated fraction of the Gammaproteobacteria differed from that detected in the clone libraries of these samples $(39.5,34.8$ and $13.6 \%$ of clones for $\mathrm{W} 1, \mathrm{~W} 2$ and $\mathrm{PS}$, respectively, and $51.2 \%$ for sample C3) (Piñar et al. 2013). Members of the phylum Actinobacteria were recovered from the enrichment cultures of samples PS and C3 (7.4 and $29.2 \%$ of the strains isolated from sample PS and $\mathrm{C} 3$, respectively), but not from the enrichment cultures of samples W1 and W2. Nevertheless, actinobacteria were represented by sequenced clones in the clone libraries of all four samples investigated $(21,32.6$ and $27.3 \%$ for samples W1, W2 and PS, respectively, and $43.9 \%$ for sample C3) (Piñar et al. 2013). The previous molecular survey also revealed the presence of sequences related to members of the phylum Bacteroidetes in all three wall samples that could not be isolated from the enrichment cultures. Attempts to isolate members of the phylum Bacteroidetes from salt-attacked monuments, which were previously detected by molecular methods, also showed to be unsuccessful in previous studies (Ettenauer et al. 2010).

Sample PS showed the highest level of bacterial diversity when molecular methods were applied, and in addition, sequences related to members belonging to the Acidobacteria, Chloroflexi, Gemmatimonadetes and Nitrospirae phyla were also detected (Piñar et al. 2013). None were retrieved as was expected, when using 3-20\% NaCl in the enrichment cultures conducted with this sample.

Furthermore, molecular analyses enabled the detection of the domain Archaea on salt efflorescences in sample $\mathrm{W} 2$, with sequences related to uncultured archaeons and to members of the genera Halococcus and Halobacterium. However, Archaea could not be isolated from the enrichment cultures of sample W2. The unsuccessful cultivation of these halophilic microorganisms on laboratory media, even using appropriate $\mathrm{NaCl}$ concentrations $(20 \% \mathrm{NaCl})$, was already reported (Piñar et al. 2009; Ettenauer et al. 2010).

It is worth noting that the genera identified by both approaches did not always coincide. On sample W1, halotolerant and halophilic species related to the genera Salinisphaera and Halomonas (Gammaproteobacteria) were detected by molecular techniques. However, they could not be isolated by cultivation techniques while 
Idiomarina sp. could. The same was observed for the Firmicutes of the order Bacillales. Sequences related to Paenibacillus sp. were detected by molecular means, but could not be isolated. In contrast, species related to the genera Oceanobacillus, Virgibacillus and Halobacillus, being dominant on the enrichment culture, could not be detected by molecular means.

On sample W2, halotolerant and halophilic species related to the genera Salinisphaera, Halomonas and Idiomarina were detected by molecular techniques, since it was possible to isolate only species belonging to the latter genus. The phylum Firmicutes was represented by species of the genus Sediminibacillus, Bacillus and Thermoactinomyces when analyzed by molecular methods. Species of the genera Bacillus, Lysinibacillus, Halobacillus and Marinococcus were isolated by culture-dependent approaches, but only species of Bacillus were detected by both approaches.

On sample PS, molecular analyses showed that the Gammaproteobacteria were represented by sequences related to the genera Cellvibrio and Moraxella, as well as by uncultured clones (Piñar et al. 2013). No representatives of these genera were retrieved from the enrichment culture of this sample, but instead species of the genus Halomonas were. Within the Actinobacteria, sequences related to the genera Rubrobacter, Nocardioides, Mycobacterium and Pseudonocardia were detected by molecular methods, but in contrast, species of the genus Arthrobacter were isolated. In addition, species of the genera Staphylococcus, Bacillus, Oceanobacillus, and Halobacillus, belonging to the phylum Firmicutes, were isolated from this sample, but its culture-independent analysis did not yield any clones harboring these sequences. A similar pitfall of molecular analysis was already observed (Ettenauer et al. 2010; Piñar et al. 2009) investigating the microflora colonizing salt-attacked monuments and has also been discussed by several authors (Laiz et al. 2003; López-Miras et al. 2013a, b).

In general, species of the genera Bacillus and Halobacillus were the most commonly isolated strains from wall samples. Strains belonging to species of these two genera were also the most commonly isolated strains in other studies attempting the isolation of halophilic microorganisms from salt-attacked monuments suffering from rosy biofilms (Ettenauer et al. 2010; Piñar et al. 2001a; Ripka et al. 2006). The viability of these organisms in such extreme habitats may be due to their osmotic adaptation through the synthesis of compatible solutes, such as glutamate, proline, ectoine and hydroxyectoine (Pittelkow and Bremer 2011) and their ability to survive unfavorable conditions as spores (Nicholson 2002), being able to regrow when favorable conditions are available.
On sample $\mathrm{C} 3$, removed from the stuffing material, sequences related to halotolerant and halophilic species of the genera Salinisphaera and Chromohalobacter were detected by molecular means (Piñar et al. 2013), as it was possible to isolate species of the latter genus from the enrichment culture, in addition to Halomonas sp. The Actinobacteria detected by molecular-based methods on this material proved to be affiliated with species of the genera Arthrobacter, Brachybacterium, Cellulomonas and Kocuria, as well as with uncultured bacterial clones associated with the microbiome (Kong et al. 2012). Using culturedependent methods, it was also possible to isolate strains most related to uncultured bacterial clones associated with the microbiome (Kong et al. 2012), as well as species of Nesterenkonia, not detected by molecular methods. Species of Nesterenkonia were also isolated from other saltattacked monuments (Ettenauer et al. 2010). In addition, species of the genera Staphylococcus, Bacillus and Virgibacillus, belonging to the phylum Firmicutes, were isolated from this sample but no clones harboring these sequences were detected in its clone library (Piñar et al. 2013).

Summarizing, the disparities in the results obtained by culture-dependent and-independent techniques in this study again demonstrate the drawbacks of each approach for an accurate description of the microbial community in a certain habitat. While giving a more complete picture of the microbial diversity of the studied environment, cultureindependent approaches mainly based on rRNA gene detection are not supplying any information about the biodegradative potential of the detected cloned sequences. In contrast, classical cultivation techniques are incapable of obtaining all members of a microbial community, but only those which are able to grow on the supplied culture media (Giovannoni et al. 1990; Hugenholtz et al. 1998; Ward et al. 1990). However, they offer the possibility to isolate the microorganisms, and to investigate their biodeteriorative capabilities in relation to a given phenomenon. Moreover, in this particular study, cultivation allowed the ability to visualize the pigmentation of the grown strains as an important agent of the aesthetical damage displayed by the investigated objects and to characterize the biodegradative capabilities of the isolated strains.

\section{Biodegradative activities of the isolated strains}

Many of the bacterial strains isolated from the wall materials displayed proteolytic activities. All isolated strains related to species of the genera Bacillus, Virgibacillus and Arthrobacter showed a strong proteolytic activity (Table 1), and so did the strains belonging to some species of the genera Oceanobacillus, Halobacillus and Idiomarina. These results are complementing those obtained in our previous survey at the Catacombs-through a culture- 
independent approach — in which, besides the halophilic microbiota, specialized microorganisms with potential degradative activities were present on and inside the mummy materials (Piñar et al. 2013). The halophilic microbiota was considered as mere contamination-due to salt detachment—and was thought to be responsible only for the rosy discoloration. Now, we know that this microbiota also possesses biodegradative abilities (proteolytic activities) that produce the degradation of the mummies positioned in direct contact with the walls (Fig. 1). The exchange of microbiota between the walls and the mummies was already notified on our previous survey, in which the presence of sequences related to pathogenic microorganisms and the human skin microbiome was detected on wall samples. In addition, some typical bacteria from the walls were detected on the bodies. The finding of these sequences was attributed to the fact that the remains were positioned directly on the walls, allowing a direct contact between wall and bodies and associated materials and the cross-contamination of these materials by microorganisms (Piñar et al. 2013).

In contrast, the cellulolytic activities detected on the strains isolated from the cellulose-rich materials used for stuffing the mummies, tow and straw, revealed a direct correlation between the deterioration of these materials and the microorganisms detected: strains related to Chromohalobacter species (C. nigrandesensis) and to Nesterenkonia (N. halobia and N. halophila) all showed cellulolytic activities. Species of these two genera have already been identified for the capability to degrade hemicelluloses (Govender et al. 2009; Kui et al. 2010; Prakash et al. 2009). The strains phylogenetically most related to an uncultured clone from the microbiome showed an individual variation, some being positive and some negative in the cellulolytic test (Table 1). The same was observed for the strains related to species of the genera Staphylococcus and Halomonas. Cellulase activities were already described for Halomonas sp. (Huang et al. 2010).

Although the hydrolytic properties of different halophilic bacteria were studied by other authors (Rohban et al. 2009; Sánchez-Porro et al. 2003), and offer a promising anticipation in a variety of biotechnological fields (Begemann et al. 2011; Setati 2010), the biodegradative assays developed in this investigation contribute to enlarge the armamentarium of microbiological media. The new media formulation enables to describe the proteolytic and cellulolytic activities of isolates using different substrates, not frequently used before, such as gelatine (skimmed milk is used often) and OBR-HEC, respectively. The crucial point during the development of these media regarded the salt precipitation. To avoid this phenomenon, different components of a specific medium were sterilized separately and then mixed together at a temperature of around $45^{\circ} \mathrm{C}$.
When all the components in a medium were autoclaved together, the resulted agar plates did not allow a reliable recognition of biodegradation zones. Such novel media can be usefully utilized in testing the proteolytic and cellulolytic abilities of other strains isolated from other $\mathrm{NaCl}-$ extreme environments, and therefore can be of valuable help in studying the characteristics of several halophylic strains.

Concerning the observed discoloration phenomena, many of the isolated strains, especially those isolated from media containing higher $\mathrm{NaCl}$ concentrations, displayed a strong pigmentation, revealing a correlation between the pigmented isolated bacteria and the discoloration of the investigated materials. On sample $\mathrm{W} 1$, showing rosy discoloration, pigmented bacteria ranging from salmon-yellowish (strains W1-1a, W1-1b, W1-3, W1-4, W1-5, W1-6, W1-10 and W1-12), salmon (strains W1-9 and W1-14) to pink color (strain W1-16) were isolated. On sample W2, taken from a yellowish salt efflorescence, the isolated bacteria showed a pigmentation that ranged from beigeyellowish (strain W2-5), salmon-yellowish (strains W2-6 and W2-7) to yellow-orange colonies (strains W2-8, W2-9, W2-10 and W2-11). The bacteria isolated from sample PS, showing purple stains, showed to be more diverse concerning the pigmentation of the isolated bacteria, ranging from yellow (strains PS4 and PS6), salmon (PS22 and PS23) salmon-yellowish (PS7b), salmon-orange (PS7, PS10, and PS11) to dark pink (PS13, PS15, PS17, PS18, PS19a, PS20 and PS24), with the latter being dominant on the sample. Sample C3, showing rosy-orange discoloration, consisted of bacteria showing pigmentation ranging from yellow (C3-2, C3-10, C3-13), salmon (C3-3) to intense orange (C3-12, C3-14 and C3-15).

\section{Conclusions}

The Capuchin Catacombs of Palermo provide a good example of a salt-attacked environment, offering a habitat for moderately and extremely halophilic microorganisms. The cultivable micro-biota inhabiting the Catacombs consists of a community highly adapted to their unique saline habitat. The predominant isolation of spore-forming bacteria, such as Halobacillus and Bacillus sp., can be explained by the fact that they can survive in unfavorable conditions: when these are again favorable, they are able to grow rapidly from their spores in the culture media. This fast growth can lead to an overestimation of the number of these microorganisms actually living on these substrates.

The two different PCR-based methods used for discrimination and clustering of the isolates, f-ITS and RAPD analyses, produced typical profiles, but also evidenced the different characters of these two molecular tools. The f-ITS 
method is suitable to cluster the isolates more at the species level, while the RAPD consents a subspecies typization.

The proteolytic and cellulolytic abilities screened through the use of plate assays showed that many of the strains isolated from the wall samples displayed proteolytic activities. In addition, many of the strains isolated from stuffing materials showed cellulolytic activities. Finally, results showed that many of the isolated microorganisms were pigmented, ranging from yellow to strong pink color and being directly related to the discoloration displayed by the materials.

Acknowledgments This study and G. Piñar were financed by the Austrian Science Fund (FWF) project "Elise-Richter V194-B20". The scholars of the EURAC-Institute for Mummies and the Iceman were generously supported by the "Stiftung Südtiroler Sparkasse" and the "Legge 14" grant of the Autonomous Province of Bolzano, Italy. The authors are indebted to Father Vincenzo Marchese, Provincial Minister of the Order of the Capuchin Friars of Palermo, as well as to Maria Elena Volpes, Superintendent to the Cultural and Environmental Heritage of Palermo, for advocating and supporting this project. Lidija McKnight, $\mathrm{PhD}$, is also acknowledged for her patient editing of the manuscript.

Open Access This article is distributed under the terms of the Creative Commons Attribution License which permits any use, distribution, and reproduction in any medium, provided the original author(s) and the source are credited.

\section{References}

Altschul SF, Madden TL, Schäffer AA, Zhang J, Zhang Z, Miller W, Lipman JD (1997) Gapped BLAST and PSI-BLAST: a new generation of protein database search programs. Nucl Acids Res 25:3389-3402

Amann RI, Ludwig W, Schleifer KH (1995) Phylogenetic identification and in situ detection of individual microbial cells without cultivation. Microbiol Rev 59:143-169

Amoroso GG, Fassina V (1983) Stone decay and conservation. Elsevier, Amsterdam

Ausubel FM, Brent R, Kingston RE, Moore DD, Seidman JG, Smith JA, Struhl K (1991) Current protocols in molecular biology. Wiley, New York

Begemann MB, Mormile MR, Paul VG, Vidt DJ (2011) Potential enhancement of biofuel production through enzymatic biomass degradation activity and biodiesel production by halophilic microorganisms. In: Ma Y, Ventosa A, Oren A (eds) Halophiles and hypersaline environments. Springer, Germany, pp 341-357

Bućková M, Puškarová A, Chovanová K, Kraková L, Ferianc P, Pangallo D (2013) A simple strategy for investigating the diversity and hydrocarbon degradation abilities of cultivable bacteria from contaminated soil. World J Microbiol Biotechnol 29:1085-1098

Donachie SP, Foster JS, Brown MV (2007) Culture clash: challenging the dogma of microbial diversity. ISME J 1:97-99

El-Rahman HAA, Fritze D, Spröer C, Claus D (2002) Two novel psychrotolerant species, Bacillus psychrotolerans sp. nov. and Bacillus psychrodurans sp. nov., which contain ornithine in their cell walls. Int J Syst Evol Microbiol 52:2127-2133

Ettenauer J, Sterflinger K, Piñar G (2010) Cultivation and molecular monitoring of halophilic microorganisms inhabiting an extreme environment presented by a salt-attacked monument. Int $\mathrm{J}$ Astrobiol 9:59-72

Giovannoni SJ, Britschgi TB, Moyer CL, Field KG (1990) Genetic diversity in Sargasso Sea bacterioplankton. Nature 345:60-63

Govender L, Naidoo L, Setati ME (2009) Isolation of hydrolase producing bacteria from Sua pan solar salterns and the production of endo-1, 4- $\beta$-xylanase from a newly isolated haloalkaliphilic Nesterenkonia sp. Afr J Biotechnol 8:5458-5466

Gurtner C, Heyrman J, Piñar G, Lubitz W, Swings J, Rölleke S (2000) Comparative analyses of the bacterial diversity on two different biodeteriorated wall paintings by DGGE and 16S rDNA sequence analysis. Int Biodeterior Biodegrad 46:229-239

Heyrman J, Swings J (2001) 16S rDNA sequence analysis of bacterial isolates from biodeteriorated mural paintings in the Servilia tomb (Necropolis of Carmona, Seville, Spain). Syst Appl Microbiol 24:417-422

Heyrman J, Balcaen A, De Vos P, Swings J (2002) Halomonas muralis sp. nov., isolated from microbial biofilms colonizing the walls and murals of the Saint-Catherine chapel (Castle Herberstein, Austria). Int J Syst Evol Microbiol 52:2049-2054

Heyrman J, Logan NA, Busse HJ, Balcaen A, Lebbe L, RodriguezDiaz M, Swings J, De Vos P (2003) Virgibacillus carmonensis sp. nov., Virgibacillus necropolis sp. nov. and Virgibacillus picturae sp. nov., three novel species isolated from deteriorated mural paintings, transfer of the species of the genus Salibacillus to Virgibacillus, as Virgibacillus marismortui comb. nov. and Virgibacillus salexigens comb. nov., and emended description of the genus Virgibacillus. Int J Syst Evol Microbiol 53:501-511

Huang X, Shao Z, Hong Y, Lin L, Li C, Huang F, Wang H, Liu Z (2010) Cel8H, a novel endoglucanase from the halophilic bacterium Halomonas sp. S66-4: molecular cloning, heterogonous expression, and biochemical characterization. J Microbiol 48:318-324

Hugenholtz P, Goebel BM, Pace NR (1998) Impact of cultureindependent studies on the emerging phylogenetic view of bacterial diversity. J Bacteriol 180:4765-4774

Imperi F, Caneva G, Cancellieri L, Ricci MA, Sodo A, Visca P (2007) The bacterial etiology of rosy discoloration of ancient wall paintings. Environ Microbiol 9:2894-2902

Ivanova EP, Romanenko LA, Chun J, Matte MH, Matte GR, Mikhailov VV, Svetashev VI, Huq A, Maugel T, Colwell RR (2000) Idiomarina gen. nov., comprising novel indigenous deepsea bacteria from the Pacific Ocean, including descriptions of two species, Idiomarina abyssalis sp. nov. and Idiomarina zobellii sp. nov. Int J Syst Evol Microbiol 50:901-907

Jensen MA, Webster JA, Straus N (1993) Rapid identification of bacteria on the basis of polymerase chain reaction-amplified ribosomal DNA spacer polymorphisms. Appl Environ Microbiol 59:945-952

Jeong DW, Kim HR, Han S, Jeon CO, Lee JH (2013) A proposal to unify two subspecies of Staphylococcus equorum: Staphylococcus equorum subsp. equorum and Staphylococcus equorum subsp. linens. Antonie Van Leeuwenhoek 104:1049-1062

Köcher S, Müller V (2011) The nature and function of carotenoids in the moderately halophilic bacterium Halobacillus halophilus. In: Ma Y, Ventosa A, Oren A (eds) Halophiles and hypersaline environments. Springer, Germany, pp 303-317

Kong HH, Oh J, Deming C et al (2012) Temporal shifts in the skin microbiome associated with disease flares and treatment in children with atopic dermatitis. Genome Res 22:850-859

Kraková L, Chovanová K, Selim SA, Šimonovičová A, Puškarová A, Maková A, Pangallo D (2012) A multiphasic approach for investigation of the microbial diversity and its biodegradative abilities in historical paper and parchment documents. Int Biodeterior Biodegrad 70:117-125 
Kui H, Luo H, Shi P, Bai Y, Yuan T, Wang Y, Yang P, Dong S, Yao B (2010) Gene cloning, expression, and characterization of a thermostable xylanase from Nesterenkonia xinjiangensis CCTCC AA001025. Appl Biochem Biotechnol 162:953-965

Kushner DJ (1978) Life in high salt and soluble concentrations: halophilic bacteria. In: Kushner DJ (ed) Microbial life in extreme environments. Academic, London, pp 317-368

Laiz L, Piñar G, Lubitz W, Saiz-Jimenez C (2003) Monitoring the colonization of monuments by bacteria: cultivation versus molecular methods. Environ Microbiol 5:72-74

Laiz L, Miller AZ, Jurado V, Akatova E, Sanchez-Moral S, Gonzalez JM, Dionísio A, Macedo MF, Saiz-Jimenez C (2009) Isolation of five Rubrobacter strains from biodeteriorated monuments. Naturwissenschaften 96:71-79

Lane DJ (1991) 16S/23S rRNA sequencing. In: Stackebrandt E, Goodfellow $M$ (eds) Nucleic acid techniques in bacterial systematics. Wiley, Chichester, pp 115-175

Li WJ, Zhang YQ, Schumann P, Liu HY, Yu LY, Zhang YQ, Stackebrandt E, Xu LH, Jiang CL (2008) Nesterenkonia halophila sp. nov., a moderately halophilic, alkalitolerant actinobacterium isolated from a saline soil. Int J Syst Evol Microbiol 58:1359-1363

López-Miras MM, Piñar G, Romero-Noguera J, Bolívar-Galiano FC, Ettenauer J, Sterflinger K, Martín-Sánchez I (2013a) Microbial communities adhering to the obverse and reverse sides of an oil painting on canvas: identification and evaluation of their biodegradative potential. Aerobiologia 29:301-314

López-Miras MM, Martín-Sánchez I, Yebra-Rodríguez A, RomeroNoguera J, Bolívar-Galiano FC, Ettenauer J, Sterflinger K, Piñar G (2013b) Contribution of the microbial communities detected on an oil painting on canvas to its biodeterioration. PLoS One 8(11):e80198

Lu J, Nogi Y, Takami H (2001) Oceanobacillus iheyensis gen. nov., sp. nov., a deep-sea extremely halotolerant and alkaliphilic species isolated from a depth of $1050 \mathrm{~m}$ on the Iheya Ridge. FEMS Microbiol Lett 205:291-297

Maturrano L, Santos F, Rosselló-Mora R, Antón J (2006) Microbial diversity in Maras salterns, a hypersaline environment in the Peruvian Andes. Appl Environ Microbiol 72:3887-3895

Nicholson WL (2002) Roles of Bacillus endospores in the environment. Cell Mol Life Sci 59:410-416

Oren A (2009) Microbial diversity and microbial abundance in saltsaturated brines: Why are the waters of hypersaline lakes red? Nat Resour Environ Issues 15 (Article 49)

Ortega-Morales BO, Narvaez-Zapata JA, Schmalenberger A, SosaLópez A, Tebbe CC (2004) Biofilms fouling ancient limestone Mayan monuments in Uxmal, Mexico-a cultivation independent analysis. Biofilms 1:79-90

Ortega-Morales BO, Gaylarde CC, Englert GE, Gaylarde PM (2005) Analysis of salt-containing biofilms on limestone buildings of the Mayan culture at Edzna, Mexico. Geomicrobiol J 22:261-268

Pangallo D, Drahovská H, Harichová J, Karelová E, Chovanová K, Aradská J, Ferianc P, Turna J, Timko J (2008) Evaluation of different PCR-based approaches for the identification and typing of environmental enterococci. Antonie Van Leeuwenhoek 93:193-203

Pangallo D, Chovanová K, Drahovská H, De Leo F, Urzì C (2009) Application of fluorescence internal transcribed spacer-PCR (f-ITS) for the cluster analysis of bacteria isolated from air and deteriorated fresco surfaces. Int Biodeterior Biodegrad 63:868-872

Peng QZ, Peng QJ, Zhang YQ, Liu ZX, Wang YX, Li WJ, Cui XL, Chen YG (2009) Halobacillus hunanensis sp. nov., a moderately halophilic bacterium isolated from a subterranean brine. Antonie Van Leeuwenhoek 96:497-504
Piñar G, Ramos C, Rölleke S, Schabereiter-Gurtner C, Vybiral D, Lubitz W, Denner EBM (2001a) Detection of indigenous Halobacillus populations in damaged ancient wall paintings and building materials: molecular monitoring and cultivation. Appl Environ Microbiol 67:4891-4895

Piñar G, Saiz-Jimenez C, Schabereiter-Gurtner C, Blanco-Valera MT, Lubitz W, Rölleke S (2001b) Archaeal communities in two disparate deteriorated ancient wall paintings: detection, identification and temporal monitoring by denaturing gradient gel electrophoresis. FEMS Microbiol Ecol 37:45-54

Piñar G, Gurtner C, Lubitz W, Rölleke S (2001c) Identification of archaea in objects of art by denaturing gradient gel electrophoresis analysis and shotgun cloning. Methods Enzymol 336:356-366

Piñar G, Ripka K, Weber J, Sterflinger K (2009) The micro-biota of a sub-surface monument the medieval chapel of St. Virgil (Vienna, Austria). Int Biodeterior Biodegrad 63:851-859

Piñar G, Piombino-Mascali D, Maixner F, Zink A, Sterflinger K (2013) Microbial survey of the mummies from the Capuchin Catacombs of Palermo, Italy: biodeterioration risk and contamination of the indoor air. FEMS Microbiol Ecol 86:341-356

Pittelkow M, Bremer E (2011) Cellular adjustments of Bacillus subtilis and other bacilli to fluctuating salinities. In: Ma Y, Ventosa A, Oren A (eds) Halophiles and hypersaline environments. Springer, Germany, pp 303-317

Power EGM (1996) RAPD typing in microbiology-a technical review. J Hosp Infect 34:247-265

Prado B, Lizama C, Aguilera M, Ramos-Cormenzana A, Fuentes S, Campos V, Monteoliva-Sánchez M (2006) Chromohalobacter nigrandesensis sp. nov., a moderately halophilic, Gram-negative bacterium isolated from Lake Tebenquiche on the Atacama Saltern, Chile. Int J Syst Evol Microbiol 56:647-651

Prakash S, Veeranagouda Y, Kyoung L, Sreeramulu K (2009) Xylanase production using inexpensive agricultural wastes and its partial characterization from a halophilic Chromohalobacter sp. TPSV 101. World J Microbiol Biotechnol 25:197-204

Ripka K, Denner E, Michaelsen A, Lubitz W, Piñar G (2006) Molecular characterisation of Halobacillus strains isolated from different medieval wall paintings and building materials in Austria. Int Biodeterior Biodegrad 58:124-132

Rohban R, Amoozegar MA, Ventosa A (2009) Screening and isolation of halophilic bacteria producing extracellular hydrolyses from Howz Soltan Lake, Iran. J Ind Microbiol Biotechnol 36:333-340

Rölleke S, Muyzer G, Wawer C, Wanner G, Lubitz W (1996) Identification of bacteria in a biodegraded wall painting by denaturing gradient gel electrophoresis of PCR-amplified gene fragments coding for $16 \mathrm{~S}$ rRNA. Appl Environ Microbiol 62:2059-2065

Rölleke S, Witte A, Wanner G, Lubitz W (1998) Medieval wall painting-a habitat for archaea: identification of archaea by denaturing gradient gel electrophoresis (DGGE) of PCR-amplified gene fragments coding 16S rRNA in a medieval wall painting. Int Biodeterior Biodegrad 41:85-92

Romano I, Lama L, Nicolaus B, Poli A, Gambacorta A, Giordano A (2006) Oceanobacillus oncorhynchi subsp. Incaldanensis subsp. nov., an alkalitolerant halophile isolated from an algal mat collected from a sulfurous spring in Campania (Italy), and emended description of Oceanobacillus oncorhynchi. Int J Syst Evol Microbiol 56:805-810

Saiz-Jimenez C, Laiz L (2000) Occurrence of halotolerant/halophilic bacterial communities in deteriorated monuments. Int Biodeterior Biodegrad 46:319-326

Sánchez-Porro C, Martín S, Mellado E, Ventosa A (2003) Diversity of moderately halophilic bacteria producing extracellular hydrolytic enzymes. J Appl Microbiol 94:295-300 
Saran S, Isar J, Saxena RK (2007) A modified method for the detection of microbial proteases on agar plates using tannic acid. J Biochem Biophys Method 70:697-699

Schabereiter-Gurtner C, Piñar G, Vybiral D, Lubitz W, Rolleke S (2001) Rubrobacter-related bacteria associated with rosy discolouration of masonry and lime wall paintings. Arch Microbiol 176:347-354

Schneegurt MA (2012) Media and conditions for the growth of halophilic and halotolerant bacteria and archaea. In: Vreeland RH (ed) Advances in understanding the biology of halophilic microorganisms. Springer, Dordrecht, pp 35-58

Setati ME (2010) Diversity and industrial potential of hydrolaseproducing halophilic/halotolerant eubacteria. Afr J Biotechnol 9:1555-1560

Spring S, Ludwig W, Márquez MC, Ventosa A, Schleifer KH (1996) Halobacillus gen. nov., with descriptions of Halobacillus litoralis sp. nov. and Halobacillus trueperi sp. nov., and transfer of Sporosarcina halophila to Halobacillus halophilus comb. nov. Int J Syst Bacteriol 46:492-496

Tomlinson GA, Hochstein LI (1976) Halobacterium saccharovorum sp. nov., a carbohydrate-metabolizing, extremely halophilic bacterium. Can J Microbiol 22:587-591

Ventosa A (2006) Unusual micro-organisms from unusual habitats: hypersaline environments. In: Logan NA, Lappin-Scott HM, Oyston PCF (eds) Prokaryotic diversity: mechanisms and significance. Cambridge University Press, Cambridge, pp 223-253
Ventosa A, Márquez MC, Garabito MJ, Arahal DR (1998) Moderately halophilic gram-positive bacterial diversity in hypersaline environments. Extremophiles 2:297-304

Ventosa A, Márquez MC, Sánchez-Porro C, de la Haba R (2012) Taxonomy of halophilic archaea and bacteria. In: Vreeland $\mathrm{RH}$ (ed) Advances in understanding the biology of halophilic microorganisms. Springer, Dordrecht, pp 59-80

Wang B, Lai Q, Cui Z, Tan T, Shao Z (2008) A pyrene-degrading consortium from deep-sea sediment of the West Pacific and its key member Cycloclasticus sp. P1. Environ Microbiol 10:1948-1963

Ward DM, Weller R, Bateson MM (1990) 16S rRNA sequences reveal numerous uncultured microorganisms in a natural community. Nature 345:63-65

Welsh J, McClelland M (1990) Fingerprinting genomes using PCR with arbitrary primers. Nucleic Acids Res 18:7213-7218

Williams JG, Kubelik AR, Livak KJ, Rafalski JA, Tingey SV (1990) DNA polymorphisms amplified by arbitrary primers are useful as genetic markers. Nucleic Acids Res 18:6531-6535

Yoon JH, Oh TK, Park YH (2004) Transfer of Bacillus halodenitrificans Denariaz et al. 1989 to the genus Virgibacillus as Virgibacillus halodenitrificans comb. nov. Int J Syst Evol Microbiol 54:2163-2167 